\title{
Search for New Plant Constituents with Potential Antiphlogistic and Antiallergic Activity
}

\author{
H. Wagner ${ }^{1}$ \\ ${ }^{1}$ Institute of Pharmaceutical Biology, University of Munich, Karlstr. 29, D-8000 München, Federal Republic of Germany
}

Received: October 14, 1988

Abstract
Structure-activity relationships obtained
from in vitro screening results obviously indicate that the
highest inhibition effects on cyclooxygenase and 5-
lipoxygenase are found amongst the class of phenolic com-
pounds (flavonoids, polyphenols, coumestans, phenolcarb-
oxylic acids) and arachidonic acid analogous (alkylamides,
retinoids, arylheptanoids, thiosulfinates, sulfinyldisulfides).
The antiinflammatory activities of some triterpenenic acids,
sesquiterpene lactones, and polysaccharides may be due to
their immunomodulating activities on the complement and/
or T-lymphocyte populations, respectively. In the search for
potential antiallergic and antiasthmatic compounds, the
thiosulfinates of onion were found to be active principles of
the drug. The mechanism of action of some other antialler-
gic plant drugs (i.e. Tylophora asthmatica, Adhatoda vas-
ica, etc.) has not yet been clarified.

\section{Introduction}

A greatly increased understanding of the biochemistry of pathophysiological inflammatory and allergic reactions together with the establishment of many new in vitro test systems for screening have stimulated the search for new antiphlogistic and antiallergic agents.

There are two fundamental strategies of in vitro screening: "shot gun" screening and "target-directed" screening. In the first of these strategies, new pharmacologically active substances are usually found with the aid of tests that are irrelevant to the subsequent application of the drug. The second method, the target-directed screening, is defined for a particular and ultimately molecular biological mode of action. There are target enzymes, target cells, and target receptors. Advantages of target-directed screening are (1) such test are specific and sometimes even organ-specific, and (2) they lend themselves very readily to automation. Enzyme tests are very reproducible and highly sensitive. These screening methods also have practical implications, with regard to operational time, cost, and especially medical ethics. It must be emphasized, however, that often the results obtained in vitro have no counterpart in vivo, i.e. in each case the in vivo efficiency has to be proven or confirmed in experimental animals and in humans.
On the other hand, these screening methods provide information on possible mechanisms of action and possibilities for structure activity studies.

\section{Screening for Antiphlogistic Agents}

The screening methods to be selected are oriented on the predominant pathogenetic and pathophysiological process. Three major pathogenetic areas are recognized today as possible sites for drug intervention (1): (a) arachidonic acid metabolism; (b) phagocytic and cell functions involved in inflammatory processes, and (c) autoimmune processes.

Current in vitro test systems employ enzyme preparations, whole cell systems, or serum fractions. Substances are screened for their capability to prevent or inhibit the formation or release of mediators or systems involved in inflammatory processes. In our screening for antiphlogistic drugs, we used the cyclooxygenase (prostaglandin synthase) from sheep seminal vesicle microsome preparation, the 5lipoxygenase from porcine leucocytes, and the complement fraction isolated from guinea pig serum (classical pathway) as well as from human serum (alternative pathway). Results obtained with enzymes and cells from other sources may differ considerably from those reported in our investigation. Furthermore, it must be emphasized that the $\mathrm{IC}_{50}$-values or percental inhibition rates are dependent on the test conditions to be used such as substrate concentration, cofactors, incubation and preincubation times. Therefore, the single test results are comparable only if certain experimental conditions are observed.

The term "antiphlogistic drug" comprises agents which intervene in acute and chronic inflammatory processes such as rheumatic diseases or arthritis. It is generally accepted that the arachidonic acid metabolism occupies one important place in these processes.

Depending on the enzyme systems of the metabolic pathway, arachidonic acid is converted into a variety of highly active metabolites. The cyclooxygenase pathway results in the formation of the stable prostaglandins, $\mathrm{PGE}_{2}, \mathrm{PGD}_{2}$, and $\mathrm{PGF}_{2 \alpha}$ as well as prostacyclin $\left(\mathrm{PGI}_{2}\right)$ and thromboxane $\mathrm{B}_{2}$, via the unstable cyclic endoperoxide intermediates, $\mathrm{PGG}_{2}$ and $\mathrm{PGH}_{2}$. The 5-lipoxygenase pathway produces leukotriene $\mathrm{B}_{4}$ and the sulfopeptide luekotrienes, $\mathrm{LTC}_{4}, \mathrm{LTD}_{4}$, and $\mathrm{LTE}_{4}$, as well as 5-hydroxyeicosatetraenoic acid (5-HETE). Most of these metabolites play an important role in processes associated with 
inflammation, such as vasodilation, increase of blood vessel permeability, pain, chemotaxis, and the allergic response (3, 4). Since prostaglandins may also affect the activity of B- and Tlymphocytes and macrophages (5), some inflammatory processes may also be influenced via this cellular mechanism.

\section{Phenol-carboxylic acids, simple phenols, flavonoids, tannins, and phenylpropane derivatives}

Following the introduction of acetylsalicylic acid as a classical nonsteroidal antirheumatic agent, innumerable structural analogues have been synthesized, but no essential improvement of activity has been achieved. Salicylic acid derivatives occur widely in many plants, but only the following plants, which contain derivatives of salicylic acid and/or salicyl alcohol, are used in phytotherapy: Salix spp., Populus tremula, Filipendula ulmaria, Gaultheria procumbens, Betula spp., Viola tricolor, and Primula elatior/offic. In the in vitro cyclooxygenase test, Salix extracts and all major compounds from willow bark, D-salicin, salicortin, salireposide, and the chalcone glucoside, isosalipurposide, were inactive up to a concentration of $250 \mu \mathrm{M}(6)$. The same negative result was reported by Flower and Vane (7) for salicylic acid and its main metabolite, salicuric acid. Nevertheless, free salicylic acid, formed in vivo in the liver by the oxidation of salicyl alcohol, exerts an antiinflammatory activity similar to that of acetylsalicylic acid (8, $9,10,11)$. We have isolated 4- and 5-methoxysalicylic acid esters (12) from Primula spp., and tested them in the cyclooxygenase test system. The most effective inhibitor was 4methoxysalicylic acid methyl ester (1), which exhibited about $50 \%$ inhibition at a concentration of $250 \mu \mathrm{M}$.

The phenolic compounds, eugenol (2), thymol, and carvacrol (3) from the essential oils of Syzygium aromaticum, Thymus vulgaris, and Ledum palustre, respectively, can be regarded as structural analogues of salicyl derivatives. The $\mathrm{IC}_{50}$ values of these compounds were found to be of the same order of magnitude as that of indomethacin $\left[\mathrm{IC}_{50}\right.$ : $1.2 \mu \mathrm{M}$ (13)]. It is of interest that acetyleugenol exhibited a stronger inhibitory effect than eugenol, which suggests that the mechanism of inhibition is similar to that of aspirin, which inhibits the enzyme by an irreversible binding of the transferred acetyl group to the protein.

When testing phenolic compounds, we observed that carvacrol showed this inhibitory activity on cyclooxygenase only in the presence of adrenalin which is usually used in the test system as a cofactor. In the absence of this cofactor, carvacrol even exhibited stimulating activity on the enzyme system up to a concentration of $10 \mu \mathrm{M}$ (14). Detailed experiments including an intact cell system (platelets) revealed that carvacrol and maybe also other phenolic compounds of a certain substitution pattern may act as electron donors and are cooxidized in the hydroperoxidase step of prostaglandin biosynthesis (14). Similar observations were made for paracetamol by Gryglewski et al. (15) and for guajacol by Egan et al. (16). Since under physiological in vivo conditions normal cells possess high peroxidase potential (17), it is compulsory to add adrenalin as a cofactor to this in vitro system or to include intact cell systems into the screening program.
Flavonoids, like salicylic acid, were introduced for therapy before they were tested for inhibitory activity in the prostaglandin metabolism. Among the flavonoids investigated by Wurm et al. $(18,19,20)$ and by Michel $(21)$, the 5,7 dihydroxyflavone galangin (4) $\left(\mathrm{IC}_{50}: 5.5 \mu \mathrm{M}\right)$ was found to be the most active cycloxygenase inhibitor.

Flavonoids with an ortho-dihydroxy structure in ring $A$ or $B$ were stronger inhibitors than those with a free 3 hydroxy group (20). Certain prenylated flavonoids, e.g. morusin, from Morus alba, were also quite active, presumably due to their higher lipophilicity $(22,23)$. Catechin was also an inhibitor of cyclooxygenase $\left(\mathrm{IC}_{50}: 130 \mu \mathrm{M}\right)(21)$.

Since tannins have been repeatedly reported to possess antiphlogistic activity (24), it is not surprising that some of them showed activity in the in vitro test. The most effective cyclooxygenase inhibitor in this class was found to be the lichen substance, 4- $O$-methylcryptochlorophaeic (5) acid $\left(\mathrm{IC}_{50}: 0.3 \mu \mathrm{M}\right)(25)$ and a gallotannin mixture consisting of tetra-, penta-, and oligo-galloylglucose, $\left(\mathrm{IC}_{50}\right.$ : approx. $\left.10 \mu \mathrm{M}\right)$ (14). Since the ellagitannins are weaker inhibitors, it seems that inhibition depends on the number of galloyl residues. A similar dependency was observed by Nishizawa et al. (26), using different enzyme systems. In view of these observations, tannins must be removed from plant extracts before screening for the presence of other potential cyclooxygenase inhibitors. As far as the mechanism of action of the gallotannins is concerned, it can be suggested that they act by scavenging oxygen radicals as has been established for the antioxidative agent gallic acid ethyl ester. In contrast, all other phenolic compounds probably act by a direct competitive reversible inhibition of the enzyme. As far as the strucutre-activity relationship in the class of plant cyclooxygenase inhibitors is concerned, it is conspicious that all compounds possess at least one phenolic group or an equivalent substitute, such as the sulfoxide group in thiosulfinates. Masking of this group reduces the inhibition effect significantly. A catechol structure does not seem to be essential. Lipophilic substituents enhance the inhibitory properties, whereas additional polar groups like in glycosides diminish or suppress them.

Numerous investigations have also been reported on the inhibitory activity of phenols, phenol-carboxylic acids, coumarins, and flavonoids in the 5 -lipoxygenase test system. The most potent inhibitors of 5-lipoxygenase are the flavonoids, quercetin, 7-hydroxyethylquercetin, cirsiol, baicalein (6), and the coumarin esculetin (7), which have $\mathrm{IC}_{50}$ values between 0.1 and about $5 \mu \mathrm{M}(27,28,29)$. The presence of a catechol structure appears to be essential for 5-lipoxygenase inhibitory activity, which suggests that such inhibitors act by a free oxygen radical scavenger mechanism. In contrast, the $\mathrm{IC}_{50}$ values of caffeic acid and other cinnamic acid derivatives are much higher ( 46 to $100 \mu \mathrm{M})$, depending on the test system used (30). The highly polar caffeic acid esters, chlorogenic acid, cichoric acid, and rosmarinic acid, are completely inactive (31). A certain degree of lipophilicity therefore appears to be a necessary requirement for an inhibitor of lipoxygenase. This agrees with our findings that wedelolactone $(8)\left(\mathrm{IC}_{50}: 2.5 \mu \mathrm{M}\right)$, isolated by us from Eclipta alba and Wedelia calendulacea, has nearly the same inhibitory activity as the most potent lipoxygenase inhibitor so far reported, i.e. nordihydroguaretic acid (NDGA; $I_{50}: 1.5 \mu \mathrm{M}$ ) (32). Chemiluminescence due to oxygen radicals is inhibited in a concentration-dependent manner 
<smiles>COc1ccc(O)c(C(C)=O)c1</smiles>

1 methyl 4-methoxysalicylate<smiles>O=c1cc(-c2ccccc2)oc2cc(O)cc(O)c12</smiles>

4 galangin<smiles>O=c1cc(-c2ccccc2)oc2cc(O)c(O)c(O)c12</smiles>

6 baicalein<smiles>COc1cc(O)c2c(c1)oc(=O)c1c3cc(O)c(O)cc3oc21</smiles>

8 wedelolactone<smiles>C=CCc1ccc(O)c(OC)c1</smiles>

2 eugenol

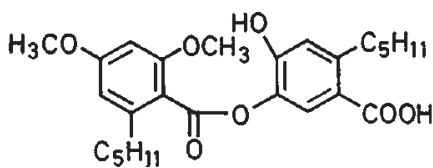

5 4-0-methylcryptochlorophaeic acid<smiles>O=c1ccc2cc(O)c(O)cc2o1</smiles>

7 esculetin<smiles>Cc1ccc(C(C)C)cc1O</smiles>

3 carvacrol tion, collectively known as urushiol (10). In the cyclooxygenase test, a urushiol reference mixture consisting of saturologous urushiol components $15: 3,15: 2,15: 1$, and $15: 0$ produced a dose-dependent inhibition with an $\mathrm{IC}_{50}$ value of $1.6 \mu \mathrm{M}$ in sheep seminal vesicles (14). Investigation of arachidonic acid metabolites in intact human platelets showed that the cyclooxygenase products, HHT and thromboxane $B_{2}$, were decreased by 60 and $70 \%$, respectively, whereas the 12 -lipoxygenase product, 12 HETE, was increased by $60 \%$. Since the same mixture also produced a strong inhibition ( $\mathrm{IC}_{50}: 2 \mu \mathrm{M}$ ) in the 5-lipoxygenase test (31), urushiol belongs to the group of dual inhibitors of arachidonic acid metabolism $(6,14)$. Dual inhibitors probably possess considerable therapeutic advantages over inhibitors of cyclooxygenase only, since it is suggested that they can prevent the so-called "substrate shift" $(37,38)$. In order to determine the contribution of urushiol to the total activity of an extract of Toxicodendron radicans (homeopathic "Ur-tincture"), we investigated the activity of ethyl acetate and chloroform extracts of the tincture in the cyclooxygenase test. We found that about half of the activity of the extract is due to urushiol, while the other half is due to gallotannins of the $\beta$-pentagalloyl-glucose type (14). An interesting result of our research is the finding that also other $n$-alkylphenols [e.g. the cardanols and cardols (11)] isolated by Schwenker et al. $(39,40)$ from Schinus terebinthifolius and Anacardium occidentale inhibit cyclooxygenase at a concentration of $10 \mu \mathrm{M}$ between 23 and $98 \%$, depending on the degree of saturation and the length of the side chain. The fact that some 5-lipoxygenase metabolites, e.g. 5-HETE and 5,12-DiHETE, were found to be lipooxygenase inhibitors has stimulated the search for further structural analogues in the fatty acid series. In addition to the above two metabolites, eicosatetraynoic acid (ETYA), which is used in the 5lipoxygenase test as a selective inhibitor of 12-lipoxygenase, is known to be a weak 5-lipoxygenase inhibitor. It is thought that ETYA is not inhibitory per se, but is metabolized to a metabolite, which acts as a so-called suicide substrate $(41,42)$. A similar mechanism is suggested for eicosapentaenoic acid (EPA), which is a main constituent of fish oils (43). Good effects of longterm therapy of chronic inflammatory diseases with EPA have been reported (44).

Even before the discovery of the 5-lipoxygenase-catalyzed arachidonic acid metabolism, psoriasis was treated with retinoids. Since the lipoxygenase inhibitor, 15HETE, has been found to be active against psoriasis, we investigated some retinoids. Only those retinoids carrying an acidic group, i.e. vitamin A acid and Etretin (12) were found to be efficient inhibitors at a concentration of $50 \mu \mathrm{M}(31)$.

Among the synthetic arachidonic acid derivatives that do not occur naturally, eicosatetraenoic hydroxamic acid - the only known $\mathrm{N}$-containing arachidonic acid derivative so far - has an $\mathrm{IC}_{50}$ value of $1.4 \mu \mathrm{M}$ (45). It is interesting that certain aliphatic amides, e.g. spilanthol (13) from Spilanthes oleracea, or dodectatetraenoic acid isobutylamide from Echinacea purpurea, are effective inhibitors of lipoxygenase, causing practically $100 \%$ inhibition at $100 \mu \mathrm{M}(46)$. The same is true for capsaicin (14), the pungent principle of Capsicum annuum, which is an efficient dual inhibitor; it has an $\mathrm{IC}_{50}$ of $3.8 \mu \mathrm{M}$ on cyclooxygenase, and inhibits 5-lipoxygenase by about $77 \%$ at a concentration of $50 \mu \mathrm{M}(13,31)$. These amides have a sharp taste and anesthetic properties. Furthermore, capsaicin is known for its skin irritating activity. A direct relationship between skin irritancy and inhibition of prostaglancans form a family of structurally related compounds possessing a $\mathrm{C}_{17}$ or $\mathrm{C}_{15}$ side chain with varying degrees of unsaturaare powerful inhibitors of cyclooxygenase $(34,35,36)$.

The alkylcatechols from Toxicodendron radi(diarylheptanoids, alkylphenols, retinoids, amides, thiosulfinates, disulfide compounds etc.)

Diarylheptanoids and phenylalkanonols, e.g. $10^{-9} \mu \mathrm{M}$. Since similar inhibitory behaviour is displayed by NDGA, the radical scavenger properties of this class of comture-activity relationships of the coumestan series, however, only be achieved under exceptionally favourable circumstances. 
<smiles>CCCCCCCCCCCCCCCCCC(=O)CC(O)[C@H](O)CCc1ccc(O)c(OC)c1</smiles><smiles>C/C=C/C=C/C/C=C/CCCCCCCc1cccc(O)c1O</smiles>

10 urushiol (15:3)<smiles>[R]c1cc(O)cc(CCCCCCC/C=C\C/C=C\CC=C)c1</smiles>

$11 R=H$ cardanol $(15: 3)$ $\mathrm{R}=\mathrm{OH}$ cardol $\quad(15: 3)$<smiles>COc1cc(C)c(/C=C/C(C)=C/C=C/C(C)=C/C(=O)O)c(C)c1C</smiles>

12 Etretin<smiles>C/C=C/C=C/CC/C=C/C(=O)NCC(C)C</smiles>

13 spilanthol<smiles>COc1cc(CNC(=O)CCCC/C=C/C(C)C)ccc1O</smiles>

14 capsaicin

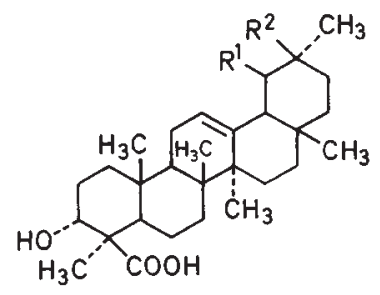

$16 \alpha, \beta$-boswellic acid<smiles>C=CCSSC=CCS(=O)CC(C)(C)C</smiles><smiles>C=C1C(=O)O[C@@H]2[C@@H]3O[C@@]4(C)CCC=C(CC[C@H]12)[C@]3(C)O4</smiles>

17 parthenolide din synthesis appears to be unlikely. It is conceivable, however, that the antiphlogistic activity of capsaicin is partly due to the so-called "counter-irritant effect" (47). This phenomenon, that a local irritant exerts additional more remote antiinflammatory effects, may be explained by a liberation of corticoids under the influence of certain cutivisceral reflexes. An alternative mechanism, which at first only appears to explain the counterirritation effect on the gastric mucosa, is that capsaicin stimulates production of the cytoprotective prostaglandins $E_{2}(47$, 48). The additional analgetic effect of capsaicin is explained by depletion of substance $P$ from primary sensory neurons associated with the transmission of thermal noxious stimuli (49).
The earliest evidence that also constituents of garlic affect the arachidonic acid metabolism was reported by Vanderhoek et al. (50). These authors showed that the metabolism of exogenous arachidonic acid by thrombocytes, i.e. the platelet synthesis of aggregation-promoting $\mathrm{TXA}_{2}$, is inhibited by oil of garlic. In our own studies, a mixture of $(E)$ - and $(Z)$-ajoene (15) showed the highest inhibition of cyclooxygenase and lipoxygenase, with $\mathrm{IC}_{50}$ values of about $5.0 \mu \mathrm{M}$ and $1.5 \mu \mathrm{M}$, respectively. These values are of the same order of magnitude as those of the reference inhibitors, indomethacin and NDGA (51). Diallyl disulfide, which is the main constituent of garlic oil, was also a good inhibitor of 5-lipoxygenase, showing an inhibition of $80 \%$ at a concentration of $50 \mu \mathrm{M}$. In contrast, other compounds, e.g. the cyclic vinyldithiines from garlic oil, were only weakly active (51). Results from the study of structure-activity relationships in the thiosulfinate series are presented in the section on antiallergic agents.

\section{Triterpenes, steroids, sesquiterpenes, and polysaccharides}

Most of these types of substances exert their antiphlogistic action by intervening in immunological reaction mechanisms. For example, a hyper-reactive complement system, characterized by formation of immune complexes and humoral inflammatory factors (52), is a contributory factor to the clinical picture of rheumatoid arthritis, acute glomerulonephritis, and systemic lupus erythematosus. In other autoimmune processes, a major part is played by hyper-reactions of the cellular defence mechanism (macrophages, T-lymphocytes) with excessive secretion of interleukins I and II (53).

Inhibition of the classical complement pathway by rosmarinic acid has already been reported by other research groups $(54,55)$. Accordingly, we have shown that other caffeic acid esters, e.g. chlorogenic acid, isochlorogenic acid, and cynarin, also inhibit complement (56). Our results with various triterpenes, however, appear to have greater therapeutic relevance $(56,57)$. The most potent inhibitor was $\alpha, \beta$-boswellic acid (16) from Boswellia serrata (incense), which caused practically $100 \%$ inhibition at a concentration of $0.1 \mu \mathrm{M}$. Glycyrrhetinic acid, which is used as its succinic half-ester (Carbenoxolon, Bigastrone ${ }^{\circledR}$ ) for the treatment of ulceration, has multiple activity. As an inhibitor of the classical complement pathway, it exerts about the same activity as boswellic acid $(56,57)$. Furthermore, it possesses corticomimetic activity, by inhibiting the corticoid degradation (58), and it also intervenes with the arachidonic acid metabolism $(59,60)$. The known antiphlogistic action of aescin (61), saikosaponins from Bupleurum falcatum (62), and saponins from Dodonea viscosa (63) is probably due to a mechanism of action similar to that of glycyrrizin. Numerous antiphlogistics acting helenaline-type sesquiterpene lactones and many of their structural variants occur in species of Arnica, Eupatorium, Tanacetum, Parthenium, and other Asteraceae. They have been investigated in various animal models by Hall et al. (64), but their exact mechanism of action is unknown. We have investigated an extract of Tanacetum (Chrysanthemum parthenium, feverfew), which is popular in England for the treatment of rheumatism and migraine. Using the measurement of chemiluminescence, we found that it suppresses TPA- and PAF-induced granulocyte activity (31). Since we established a similar activity for the main constituent of the drug, parthenolide (17) (31), it is possible that sesquiterpene lactones act upon protein kinase $\mathrm{C}$ of granulo- 
cytes. This enzyme increases $\mathrm{PLA}_{2}$ activity by increasing lipocortin binding, thereby causing an increase of arachidonic acid metabolism. Inhibition of protein kinase $C$ therefore leads indirectly to an inhibition of arachidonic acid metabolism. Such a reaction mechanism would agree with the observations of Heptinstall et al. $(65,66)$, Hayes et al. $(67)$, and other authors $(68,69,70)$.

A scavenging effect for oxygen radicals could be ruled out as measured by the chemiluminescence method using the cell-free purine xanthinoxidase system.

In this connection, it is interesting that an antiphlogistic principle of the fruit juice of Ecballium elaterium, which is applied externally in a diluted form for the treatment of sinusitis in Turkey, has been identified as curcurbitacin B (71). After oral administration to the mouse, the inhibition of vascular permeability was measured by the Whittle method (72). At a dose of $200 \mathrm{mg} / \mathrm{kg}$, the inhibition was $70 \%$ and significantly greater than that achieved with aspirin. The action mechanism is unknown, but in view of the strong irritant action of cucurbitacins, a so-called "counter-irritant effect" is probably operative. Since cucurbitacins are the characteristic constituents of Bryonia dioica, which has been commonly used for the treatment of rheumatism and gout, one can suggest that it acts via the same or a similar mechanism of action. In contrast, the antiphlogistic and antirheumatic action of steroids from Withania somnifera and Lycium chinensis appears to be due to suppression of T-lymphocytes $(73,74,75)$.

Amongst the high molecular mass compounds, we found that highly sulfated polysaccharides, e.g. fucoidin, caused a marked reduction of hemolysis in the in vitro complement test of Kabat and Mayer (76) (classical pathway), whereas acidic polysaccharides were inactive $(56,57)$. Carrageenan showed $100 \%$ effect down to $2.5 \mu \mathrm{g} / \mathrm{ml}$, whereas the alginates, fucoidin and laminarin, caused $100 \%$ reduction of hemolysis down to concentrations of 7.5 and $10 \mu \mathrm{g} / \mathrm{ml}$, respectively. With the known complement inhibitor heparin, this effect could be achieved only at concentrations above $750 \mu \mathrm{g} / \mathrm{ml}$. In the alternative complement test of Platts-Mills (77), the sulfated polysaccharides were found to be active only at much higher concentrations. From this we conclude that the main site of action of these polysaccharides lies before the $C 3$ part of the complement system. These findings are supported by the recent work of Baker et al. (78), which suggests that the strongly negatively charged carrageenan has an activating influence on the complement component $\mathrm{C} 1$. Other studies indicate that carrageenan, dextran sulfate, and similar polysaccharides might be inhibitors of the complement system (79). These different interpretations of the mechanism of action arise from the different evaluation of the test systems. In screening procedures, when total complement is used $\mathrm{TCH}_{50}$, $\mathrm{ACH}_{50}$ ), utilization of complement as the result of an activation reaction can be misinterpreted as inhibition. The nature of the effect on the complement system can therefore be established only by investigation of the separate complement components.

A $1 \rightarrow 3 \beta$-linked glucan from Lentinus edodes (80) and an arabinogalactan from berries of Viscum album $(56$, 81) were found to activate the alternative pathway at a concentration of $1000 \mu \mathrm{g} / \mathrm{ml}$. A similar activity was obtained by a protein containing arabinogalactan from Angelica acutiloba, an acidic heteroglucan from Artemesia princeps, and an acidic polysaccharide from Lithospermum euchromum, whereas an acetylated glucuronoarabinoxylan activated both the classical and the alternative pathways of the complement system (82).

It has recently been suggested that the complement system is involved in acute inflammatory processes, as represented by the rat paw edema test, even though the exact mechanism of action of polysaccharides in this assay is unknown (83). Using this animal model, polysaccharides from the following sources were found to have good antiinflammatory properties: Sabal serrulata (84), Echinacea purpurea (85), Dictyophora indusiata (6), fruits of Auricularia spp. (87), and the roots of Urtica dioica (88).

\section{Screening for Antiallergic Agents}

Allergic asthma is one of the most serious of the allergic complaints. It is triggered by an immediate allergic response, mediated by IgE-type antibodies. Mast cells and other effector cells are involved, and in the actual onset of the asthmatic attack, a major role is played by sulfopeptide leukotrienes (anaphylactic slow reacting substances), PAF, and oxygen radicals, as well as histamine. The currently used antiasthmatic drugs, ephedrine, theophylline, and atropine, do not act (or only partially) in these IgE-mediated pathophysiological processes. They exert their activities indirectly as $\beta_{2}$-sympathomimetic or anticholinergic agents. Corticoids do not influence the immediate allergic response. They do, however, have antiallergic activity in the delayed allergic phase, due to inhibition of arachidonic acid liberation at the level of phospholipase $\mathrm{A}_{2}$. Cromoglycic acid stabilizes the mast cell membrane and inhibits IgE-promoted release of mediators, but it is effective only when applied before exposure to the antigen, and it must be inhaled (see also review 89,90 ).

The selection of suitable in vitro and in vivo model systems has to be oriented on the pathophysiology of the relevant illness $(89,90)$. In addition to mast cells, other possible target cells are eosinophils and neutrophilic granulocytes, macrophages and T-lymphocytes. The most important target enzymes are 5-lipoxygenase and phospholipase $A_{2}$. For the determination of the effect of drugs on bronchial obstruction, both invasive and noninvasive procedures are available. Noninvasive, whole body plethysmography is a sensitive method for the measurement of lung function, applicable to both guinea pigs and humans, which determines e.g. the parameter of "compressed air" (91). Using this method, we were able to localize the antiasthmatic principle of Allium cepa $(92,93,94)$. These studies were preceded by investigations in which patients with extrinsic asthma were submitted to two bronchial provocation tests at an interval of 4 weeks, using the same allergen dose. The first test was performed without pretreatment. In the second test, the patient obtained $100 \mathrm{ml}$ of a $5 \%$ ethanolic extract of $200 \mathrm{~g}$ of onions one hour before and two hours after the administration of the allergen. The measured analytical parameter was "compressed air". Allergen-induced asthma attacks were suppressed almost totally by this onion extract medication. This experiment was repeated with guinea pigs, using PAF or ovalbumin for the provocation, and determining the degree of bronchial obstruction by whole body plethysmography. The maximal dose of $100 \mathrm{mg} / \mathrm{kg}$ crude onion extract caused more than $90 \%$ inhibition of bronchial asthma. Doses of 20 and $50 \mathrm{mg} / \mathrm{kg}$ still had a beneficial effect, whereas $1 \mathrm{mg} / \mathrm{kg}$ was no longer active. Using this animal model, we have shown that the 
antiasthmatic principle of Allium cepa has to be localized in the chloroform extract of the onion juice. We isolated 13 sulfurcontaining substances from this lipophilic fraction $(93,94,95)$. Amongst those, twelve are entirely new, belonging to various classes of compounds, including thiosulfinates (18), dithietanes, and $\alpha$-sulfinyldisulfides (19). The last of these we have named cepaenes, in analogy with the naming of ajoenes from garlic. Since the dithietanes were inactive in the animal model, the main antiasthmatic activity of the onion extract would appear to be due to the thiosulfinates. The cepaenes, although highly active in vitro, have not been isolated in the necessary amount to be evaluated for their in vivo activities. In order to obtain more information on the mechanism of action of the isolated compounds, in vitro studies were also performed on the onion compounds available in sufficient quantities. Some thiosulfinates were synthesized and also included in these experiments. It was found that some of the thiosulfinates also dislayed a structure- and dose-dependent inhibition of cyclooxygenase and 5-lipoxygenase $(93,94)$. Of the isolated thiosulfinates, the $\alpha, \beta$-unsaturated compounds were especially active, while the most active of the synthetic compounds were mono- and diphenyl derivatives, respectively. In both test systems, however, the cepaenes were more active than the thiosulfinates. On the other hand, thiosulfinates were active inhibitors of histamine release, thromboxane synthesis, and chemiluminescence (95). Onion constituents therefore differ markedly in their mode of action from the antiasthmatic drugs used in therapy today. Since they would appear to be active by oral application they are obviously promising candidates for clinical investigation. Which type of drug will be most appropriate one for therapeutic purposes, i.e. standardized onion extracts, natural or chemically modified thiosulfinates, has to be investigated. Using the methods described above, it should be possible in the near future to discover other plant constituents with potential antiallergic and antiasthmatic activity. Sankawa and Chun (96) screened 20 drugs from traditional Chinese medicine, which are claimed to be effective in allergic asthma, using the passive cutaneous anaphylaxis test (type 1 immediate response). Ten plant extracts showed good inhibition effects $(100-300 \mathrm{mg} / \mathrm{kg} i . v$.). In subsequent tests, using an in vitro mast cell model, highly methoxylated compounds isolated from Citrus aurantium, e.g. nobeletin, 3,4,6,7,8,3',4'-heptamethoxyflavone, tangeretin, and others, were found to be good inhibitors. Flavonoids, a coumarin, a neolignan, and sesquiterpenes with antiallergic properties were likewise isolated from Magnolia salicifolia and Centipeda minima. An $N$-isobutyl3,4-methylenedioxybenzamide with antihistamine activity has been isolated from Asarum sagittarioides by another Japanese research group (97). The antihistamine activity of this compound could be improve by chemical modification.

Of the flavones, baicalein from Scutellaria baicalensis has already been reported to be an antiallergic compound on the basis of its inhibition of the hypersensitive immediate response (98) and of thrombocyte lipoxygenase (99). Apparently, the unfavourable pharmacokinetics and low bioavailability of baicalein, like those of many other flavonoids, have so far prevented its therapeutic application. Inhibition of histamine release from mast cells by other flavonoids and biflavonoids has been reported (100), and this activity is possibly due to an inhibition of cAMP-phosphodiesterase. Drugs with both antiallergic and antiasthmatic properties are known from the Ayurvedic medicine, i.e. Tylophora asthmatica and Adhatoda vasica. The non-anticholinergic and antihistamine<smiles>[R]SS([R])=O</smiles><smiles>[R]SSC(CC)S([R])=O</smiles>

$R^{\prime}, R^{2}=\mathrm{CH}_{3}, n-\mathrm{C}_{3} \mathrm{H}_{7},-\mathrm{CH}_{2}-\mathrm{CH}=\mathrm{CH}_{2}$,

$\mathrm{R}^{\prime}=-\mathrm{CH}=\mathrm{CH}-\mathrm{CH}_{3}$ $-\mathrm{CH}=\mathrm{CH}-\mathrm{CH}_{3}, \mathrm{C}_{6} \mathrm{H}_{5}$

$\mathrm{R}^{2}=-\mathrm{CH}=\mathrm{CH}-\mathrm{CH}_{3}, \mathrm{n}-1$

18 thiosulfinates

19 cepaenes<smiles>COc1cc2c3c(c4cc(OC)c(OC)cc4c2cc1OC)=CN1CCCC1C=3</smiles><smiles>O=c1c2ccccc2nc2n1CCC2</smiles>

21 vasicinone

mechanism of action of the first of these drugs still requires clarification. It may be assumed, however, that the Tylophora alkaloids (20) play a decisive role in the antiasthmatic activity (101). Comprehensive pharmacological investigations have been reported on the second of these drugs $(102,103)$. A combination of the two alkaloids, vasicine and vasicinone (21), showed bronchodilatory activity comparable to that of theophylline and greater than that achieved with each alkaloid separately $(102,103)$. The mechanism of action is thought to be anticholinergic.

\section{References}

1 Arrigoni-Martelli (1982) Future Directions in Anti-rheumatic Research. In: Drugs of the Future, Vol. VII, 9, 663.

${ }^{2}$ Greyglewski, R. I. (1979) in: Handbook of Experimental Pharmacology, Vol. 50/II (Vane, J. R., Ferreira, S. H., eds.), Springer Verlag, Heidelberg - Berlin - New York.

3 Schrör, K. (1984) Prostaglandine und verwandte Verbindungen, G. Thieme Verlag, Stuttgart - New York.

${ }^{4}$ Kirckpatrick, C. J., Mohr, W., Haferkamp, O. (1982) Z. Rheumatol. 41.89 .

5 Morley, J. (1978) Lymphokine 4, 377.

6 Wagner, H. (1987) Phytotherapie 8, 135.

${ }^{7}$ Flower, R. J., Vane, J. R. (1974) in: Prostaglandin Synthetase Inhibitors (Robinson, H. J., Vane, J. R., eds.), Raven Press, New York, pp. 9-18.

8 Whitehouse, M. W., Rainsford, K. D., Ardlie, N. G., Young, I. G., Brune, K. (1977) in: Proceedings of the Symposium on Aspirin and Related Drugs: Their Actions and Uses (Rainsford, K. D., Brune, K., Whitehouse, M. W., eds.), Birkhäuser Verlag, Basel - Stuttgart, pp. 43-57.

9 Hamberg, M. (1972) Biochem. Biophys. Res. Commun. 49, 720726.

${ }^{10}$ Ferreira, S. H., Vane, J. R. (1979) in: Handbock of Experimental Pharmacology, Vol. 50/II (Vane, I. R., Ferreira, S. H., eds.), Springer-Verlag, Heidelberg - Berlin - New York, p. 371.

11 Higgs, G. A., Salmon, J. A., Henderson, B., Vane, J. R. (1987) Proc. Natl. Acad. Sci. USA 84, 1417-1420.

12 Wagner, H., Reger, H. (1987) Dtsch. Apoth. Ztg. 126, 2613.

13 Wagner, H., Wierer, M., Bauer, R. (1986) Planta Med. 54, 184.

${ }^{14}$ Wierer, M. (1988) Thesis, München.

15 Robak, J., Wieckowski, A., Gryglewski, R. J. (1978) Biochem. Pharmacol. 27, 393.

16 Egan, R. W., Gale, P. H., Beveridge, G. C., Marnett, L. J., Kuehl, F. A., Jr. (1980) in: Advances in Prostaglandin and Thromboxane Research Vol. 6 (Samuelsson, B., Ramwell, P. W., Paoletti, R., eds.), Raven Press, New York, pp. 153-155.

17 Lands, W. E. M., Hanel, A. M. (1982) Prostaglandins 25, 271.

18 Baumann, J., Bruchhausen, F. v., Wurm, G. (1980) Prostaglandins 20, 627-639. 
19 Baumann, J., Wurm, G., Bruchhausen, F. v. (1980) Arch. Pharm. $313,330-337$.

20 Wurm, G., Baumann, J., Geres, U. (1982) Dtsch. Apoth. Ztg. 122, $2062-2078$

21 Michel, F., Mercklein, L., Rey, R., Crastes de Paulet, A. (1985) in: Flavonoids and Bioflavonoids (Farkas, L., Gabor, M., Kallay, F., eds.), Budapest, pp. 389-401.

22 Kimura, Y., Okuda, H., Nomura, T., Fukai, T., Arichi, S. (1986) Chem. Pharm. Bull. 34, 1223-1227.

${ }^{23}$ Evans, A. T., Formukong, E., Evans, F. J. (1987) Biochem. Pharmacol. 36, 2035-2037.

${ }^{24}$ Kimura, Y., Okuda, H., Okuda, T., Arichi, S. (1986) Planta Med. 54, $337-338$.

${ }^{25}$ Sankawa, U., Shibuya, M., Ebizuka, Y., Noguchi, H., Kinoshita, T., litaka, Y. (1982) Prostaglandins 24, 21-34.

${ }^{26}$ Nishizawa, M., Yamagishi, T., Ohyama, T. (1983) Chem. Pharm. Bull. 31, 2150-2152.

27 Yoshimoto, T., Furukawa, M., Yamamoto, S., Horie, T., WatanabeKohno, S. (1983) Biochem. Biophys. Res. Commun. 116, 612.

${ }^{28}$ Furukawa, M., Joshimoto, T., Ochi, K., Yamamoto, S. (1984) Biochem. Biophys. Acta 795, 458.

${ }^{29}$ Hope, W. C., Welton, A. F., Fiedler-Nagy, C., Batula-Bernard, C., Coffey, J. W. (1983) Biochem. Pharm. 32, 367.

${ }^{30}$ Furukawa, M., Yoshimoto, T., Ochi, K., Yamamoto, S. (1984) Biochim. Biophys. Acta 795, 458.

31 Fessler, B. (1988) Thesis, München.

32 Wagner, H., Fessler, B. (1986) Planta Med. 54, 343.

33 Wong, S. M., Antus, S., Gottsegen, A., Fessler, B., Rao, G. S., Sonnenbichler, J., Wagner, H. (1988) Arzneimittel-Forsch. (Drug Res.) 38,661 .

${ }^{34}$ Kiuchi, F., Shibuya, M., Sankawa, U. (1982) Chem. Pharm. Bull. 30, $2279-2282$.

35 Kiuchi, F., Shibuya, M., Sankawa, U. (1982) Chem. Pharm. Bull. 30, 754-757.

${ }^{36}$ Iwakami, S., Shibuya, M., Tseng, C. F., Hanaoka, F., Sanakawa, U. (1986) Chem. Pharm. Bull. 34, 3960-3963.

37 Kuehl, F. A., Dougherty, H. W., Ham, E. A. (1984) Biochem. Pharmacol 33, 1-5.

${ }^{38}$ Higgs, G. A., Flower, R. J., Vane, J. R. (1979) Biochem. Pharmacol. $28,1959-1961$.

${ }^{39}$ Skopp, G., Opferkuch, H. J., Schwenker, G. (1986) Z. Naturforsch. $42 \mathrm{c}, 7-16$.

40 Skopp, G. (1986) Thesis, University of Heidelberg.

41 Smith, W. L., Lands, W. E. M. (1970) Biochem. Biophys. Res. Commun. $41,846$.

42 Downing, D. T., Ahern, D. G., Bachta, M. (1970) Biochem. Biophys. Res. Commun. 40, 218.

${ }^{43}$ Weber, P. C. P., Schacky, C., Lorenz, R. (1986) Dtsch. Apoth. Ztg. 1/ 2,4

44 Fisher, M., Upchurch, K. S., Levine, P. H., Johson, M. H., Vandrenil, C. H., Natale, A., Hoogasian, J. J. (1986) Inflammation 10, 387.

45 Kerdesky, F. A. J., Holms, J. H., Schmidt, S. P., Dyer, R. D., Carter, G. W. (1985) Tetrahedron Lett. 26, 2143

${ }_{46}$ Breu, W., Thesis, University of München, in preparation.

47 Atkinson, D. C., Hicks, R. (1975) Agents and Actions 5, 239.

48 Dearden, J. C., Nicholson, R. M. (1984) J. Pharm. Pharmacol. 36, 713.

49 Yaksh, T. L., Farb, D. H., Leemann, S. E., Jesell, Th. M. (1979) Science 206, 481 .

${ }^{50}$ Vanderhoek, J. Y., Makheja, A. N., Bailey, J. M. (1980) Biochem. Pharmacol. 29, 3169.

51 Wagner, H., Wierer, M., Fessler, B. (1987) Planta Med. 55, 305.

52 Benacerraf, B., Unanue, E. (1982) Immunologie, W. de Gruyter Verlag, Berlin.

53 Otterness, I. G., Bliven, M. L. (1982) in: Therapeutic Control of Inflammatory Diseases, Advances in Inflammation Research, Vol. 7 (Otterness, I., Capetols, R., Wong, St., eds.) Raven Press, New York, p. 185.

54 US Pat. 4.379361, 11. May, 1982; Europ. Patent Appl. No. 80107752.0, Ball 81/4 (1981).

55 Garcza, L., Koch, H., Löffler, E. (1985) Arch. Pharm. 318, 1090

56 Wagner, H., Knaus, W., Jordan, E. (1987) Z. Phytotherapie 8, 148.

57 Knaus, U., Thesis, München, in preparation.

${ }^{58}$ Kumazi, A., Yano, S., Otomo, M., Takeuchi, K. (1957) Endocrinol. Jpn. $4,17$.
59 Inove, H., Saito, K., Koshihàra, Y., Muroto, S. (1986) Chem. Pharm. Bull. 34, 897

60 Tamura, Y., Nishikawa, T., Yamada, K., Yamamoto, M., Kumagai, A. (1979) Arzneimittel-Forsch. (Drug Res.) 29, 647.

61 Hiai, S., Yokoyama, H., Oura, H. (1981) Chem. Pharm. Bull. 29, 490.

62 Yamamoto, M., Kumagai, A., Yamamura, Y. (1975) Arzneim.Forsch. (Drug Res.) 25, 1021.

${ }^{63}$ Wagner, H., Ludwig, C., Grotjahn, L., Kahn, M. S. Y. (1987) Phytochemistry 26, 697.

64 Hall, I. H., Lee, K. H., Starnes, C. 0., Sumida, Y., Wu, R. Y., Waddell, T. G., Cochran, J. W., Gerhart, K. G. (1979) J. Pharm. Sci. 68, 537.

${ }^{65}$ Heptinstall, S., White, A., Williamson, L., Mitchell, J. R. A. (1985) Lancet I, 1071.

${ }^{66}$ Heptinstall, S., Groenewegen, W. A., Spangenberg, P., Loesche, W. (1987) J. Pharm. Pharmacol. 39, 459.

67 Hayes, N. A., Foreman, J. C. (1987) J. Pharm. Pharmacol. 39, 466.

${ }^{68}$ Collier, H. O. J., Butt, N. M., McDonald Gibson, W. J., Saeed, S. A. (1980) Lancet II, 922.

69 Capasso, F. (1986) J. Pharm. Pharmacol. 38, 71

${ }^{70}$ Makheja, A. N., Bailey, J. M. (1981) Lancet II, 1054.

71 Yesilada, E., Tanaka, S., Sezik, E., Tabata, M. (1988) J. Nat. Prod. 51,504 .

72 Whittle, B. A. (1964) Brit. J. Pharmacol. 22, 246.

73 Bähr, V., Hänsel, R. (1982) Planta Med. 44, 32.

74 Yun-Choi, H. S., Kim. S. O., Kim, J. H., Lee, J. R. (1985) J. Nat. Prod. 48,363

75 Sudhir, S., Budhiraja, R. D., Miglani, G. P., Arora, B., Gupra, L. C., Garg, K. N. (1986) Planta Med. 53, 61.

${ }^{76}$ Kabat, E. A., Mayer, M. M. (1961) Kabat and Mayers' Exp. Immunochemistry, 2nd. Ed., Ch. C. Thomas, Springfield, USA, p. 133.

77 Platts-Mills, T. A. E., Ishizaka, K. (1974) J. Immunol. 113, 348.

78 Bahor, K. C., Nicklin, S., Miller, K. (1986) Fd. Chem. Toxic. Vol. 24, 889 .

79 Davies, G. E. (1963) Immunology 6, 561

80 Yamada, H., Nagai, T. (1986) Carbohydr. Res. 156, 137.

81 Wagner, H., Jordan, E. (1988) Phytochemistry 27, 2511

82 Yamada, H., Nagai, T. (1986) Carbohydr. Res. 156, 137-145.

83 Di Rosa, M., Giroud, J. P. (1971) J. Path. 104, 15-28.

${ }^{84}$ Wagner, H., Flachsbarth, H., Vogel, G. (1981) Planta Med. 41, 252; $42,244$.

85 Tubaro, A., Tragni, E., Del Negro, P., Galli, C. L., Della Loggia, R. (1987) J. Pharm. Pharmacol. 39, 567.

${ }^{86}$ Hara, C., Kiho, T., Tanaka, Y., Ukai, S. (1987) Carbohydr. Res. 110, 77.

87 Kiho, T., Sakai, M., Ukai, S., Hara, C., Tanaka, Y. (1985) Carbohydr. Res. $142,334$.

88 Willer, F., Thesis, University of München, in preparation.

${ }^{89}$ Dorsch, W. (1986) Allergologie 9, 419

90 Schwendner, C. F. (1983) Drugs of the Future 8, 699.

91 Baetz, M., Dorsch, W. (1987) Allergologie 10, 304

92 Dorsch, W., Adelmann-Grill, B., Bayer, Th., Ettl, M., Hein, G., Jaggy, J., Ring, Scheftner, P., Wagner, H. (1987) Allergologie 10, 316.

${ }^{33}$ Dorsch, W., Wagner, H., Bayer, Th., Fessler, B., Hein, G., Ring, F., Scheftner, P., Sieber, W., Strasser, Th., Weiß, E. (1989) Biochemical Pharmacology, in press.

94 Wagner, H., Bayer, Th., Dorsch, W. (1989) Z. Phytotherapie, 9, 165 (1988).

${ }^{95}$ Bayer, Th. (1988) Thesis, University opf München.

96 Sankawa, K., Chuin, Y.-T. (1985) Antiallergic substances from Chinese Medicinal Plants in Advances in Chinese Medicinal Materials Research, (Chang, H. M., Young, H. W., Tso, W.-W., Koo, A., eds.) World Scientific Publ. Co., Singapore.

97 Terada, S., Motomiya, T., Yoshioka, K., Narita, T., Yasui, S., Tahase, M. (1987) Chem. Pharm. Bull. 35, 2437.

98 Koda, A., Nagai, H., Wada, H. (1970) Folia Pharmacol. Japon. 66, 237.

99 Sekiya, O., Okuda, H. (1982) Biochem. Biophys. Res. Commun. 105, 1090.

100 Amellal, M., Bronner, C., Briancon, F., Haag, M., Anton, R., Landry, Y. (1985) Planta Med. 16

101 Rao, K. V., Wilson, R. A., Cummings, B. J. (1971) Pharm. Sci. 60, 1725.

102 Gupta, O. P., Sharma, M. L., Ghatak, B. I. R., Atal, C. K. (1977) Ind. J. Med. Res. 66, 680 .

103 Cambridge, G. W., Jansen, A. B. A., Jarman, D. A. (1962) Nature (London) 196, 1217. 